\title{
Diabetes Flow Sheet Use Associated With Guideline Adherence
}

\author{
Karissa A. Habn, MPH \\ Jeanne M. Ferrante, $M D^{2,3}$ \\ Jesse C. Crosson, $\mathrm{PhD}^{1,2}$ \\ Shawna V. Hudson, $P h D^{1,3}$ \\ Benjamin F. Crabtree, $\mathrm{PbD}^{1,3}$ \\ 'UMDNJ - Robert Wood Johnson Medical \\ School, Department of Family Medicine, \\ Somerset, New Jersey \\ ${ }^{2}$ UMDNJ - New Jersey Medical School, \\ Department of Family Medicine, Newark \\ ${ }^{3}$ The Cancer Institute of New Jersey, \\ New Brunswick
}

Conflicts of interest: none reported

\section{CORRESPONDING AUTHOR}

Karissa A. Hahn, MPH

Department of Family Medicine UMDNJ-RWJMS

1 World's Fair Dr, 1st Floor

Somerset, NJ 08873

clarkeka@umdnj.edu

\begin{abstract}
PURPOSE Many intervention studies have found that flow sheet use improves patient care by drawing attention to a particular medical condition or needed preventive service and encouraging an immediate response from the health care professional; however, there are no studies examining how often flow sheets are used for diabetes in primary care practice. We assessed the relationship between diabetes flow sheet use and diabetes patient care outcomes in the everyday practice of primary care.
\end{abstract}

METHODS We abstracted the medical records of 1,016 patients with diabetes seen at 54 New Jersey and eastern Pennsylvania family practices participating in a quality improvement trial. The use of diabetes flow sheets was noted for each medical record. Scores for adherence to evidence-based diabetes guidelines in terms of assessment, treatment, and target attainment were determined on 100point scales, with higher scores indicating better adherence. Generalized linear models were used to determine associations between use of diabetes flow sheets and adherence to guidelines.

RESULTS Diabetes flow sheets were used in 23\% of the medical records of patients with diabetes. Use of flow sheets was associated with better mean guideline adherence scores for the assessment of diabetes ( 55.38 vs 50.13 , $P=.02$ ) and the treatment of diabetes (79.59 vs 74.71, $P=.004$ ), but not for the attainment of intermediate diabetes outcome targets (hemoglobin $A_{1 c}$ level, lowdensity lipoprotein cholesterol level, and blood pressure).

CONCLUSIONS Diabetes flow sheets can be used to promote better adherence to guidelines when it comes to assessing and treating diabetes. Additional research is needed to explore patient and physician variables that mediate the relationship between use of diabetes flow sheets and intermediate outcome targets for diabetes.

Ann Fam Med 2008;6:235-238. DOI: 10.1370/afm.812.

\section{INTRODUCTION}

S everal studies have shown the efficacy of disease-specific flow sheet use for improving patient care $^{1.7}$; however, there are no studies in primary care settings examining how often flow sheets are used to guide diabetes care or the effectiveness of diabetes flow sheet use for improving patient outcomes. We undertook a study to describe the relationship between diabetes flow sheet use and patient care outcomes in the everyday practice of primary care.

\section{METHODS}

We used baseline data collected by retrospectively abstracting medical records in $54 \mathrm{New}$ Jersey and eastern Pennsylvania family medicine practices participating in the ULTRA (Using Learning Teams for Reflective Adaptation) quality improvement intervention trial, which was designed to evaluate the effectiveness of a facilitated team-building intervention in 
improving adherence to guidelines for multiple chronic diseases. ${ }^{8}$ Practices owned and primarily staffed by family physicians were sampled from the New Jersey Family Medicine Research Network (NJFMRN) and the Eastern Pennsylvania Inquiry Collaborative Network (EPICnet); practices recommended by others knowledgeable about local practices were sampled as well. To be eligible to participate in the project, practices had to be in existence for at least 1 year and be willing to comply with the study protocol for 5 years. Approximately $48 \%$ of practices provided with detailed information about the study agreed to participate. The University of Medicine and Dentistry of New Jersey - Robert Wood Johnson Medical School Institutional Review Board approved this study.

Each participating practice generated a list of patients coded for insurance purposes for diabetes during the previous 12 months. Patients were excluded if they were deceased, were younger than age 18, were no longer a patient of the practice, or did not have at least 1 visit for diabetes in the previous 12 months. Within each practice, approximately 20 patients were randomly selected from the list, for a total of 1,016 patients.

Research nurses were trained by a physician to collect information from progress notes, laboratory results, and flow sheets of medical records on a structured survey instrument. Nurses recorded process and outcome data for diabetes care and information on the organization of the medical record, including the use of diabetes flow sheets. Flow sheets were considered "used" if they were present in the paper or electronic medical record and had at least 1 piece of information recorded on them. For practices with electronic medical records, we accepted data that were either manually or automatically entered into flow sheets.

Our main outcome of interest was adherence to diabetes guidelines recommended by the National Diabetes Education Program (NDEP). ${ }^{9}$ A multidisciplinary research team developed adherence scores for diabetes assessment, treatment, and target attainment based on these guidelines. The scoring and weights for guideline adherence were subsequently reviewed by independent consultants. Similar scoring algorithms have been used in previous analyses for diabetes as well as for hyperlipidemia. ${ }^{10-13}$

Diabetes assessment scores were based on documentation in the medical record of 5 assessments: hemoglobin $A_{1 c}$ level tested in the past 6 months, urine microalbumin level tested in the past year, lowdensity lipoprotein (LDL)-cholesterol level tested in the past year, smoking status, and blood pressure. Each item was given 20 points if documented and 0 if not documented, for a total possible assessment score of 100 .
Diabetes treatment scores consisted of documentation in the medical record of 4 measures: LDL-cholesterol level below $100 \mathrm{mg} / \mathrm{dL}$ or use of a lipid-lowering agent, hemoglobin $\mathrm{A}_{1 \mathrm{c}}$ level at or below $8 \%$ or use of a hypoglycemic agent, blood pressure at or below 130/85 $\mathrm{mm} \mathrm{Hg}$ or use of an antihypertensive agent, and urine microalbumin level below $30 \mathrm{mg} / \mathrm{g}$ creatinine or use of an angiotensin-converting enzyme (ACE) inhibitor or angiotensin II receptor blocker (ARB). Each item was given 25 points if documented and 0 if not documented, for a total possible treatment score of 100 .

Diabetes target attainment scores consisted of documentation in the medical record of attainment of 3 targets: hemoglobin $\mathrm{A}_{1 \mathrm{c}}$ level less than 8\%, LDL-cholesterol level less than or equal to $100 \mathrm{mg} / \mathrm{dL}$, and blood pressure less than or equal to $130 / 85 \mathrm{~mm} \mathrm{Hg}$. Each item was given 33.3 points if documented and 0 if not documented, for a total possible target attainment score of 100 .

The main independent variable of interest was use of flow sheets for diabetes care.

We conducted data analysis using SAS version 9.1 (SAS Institute Inc, Cary, North Carolina). ${ }^{14}$ The guideline algorithm detailed above was used to calculate guideline adherence scores for each patient. Generalized linear models with random effects to account for clustering of patients within practice were used to determine associations between flow sheet use and guideline adherence scores. At the practice level, we controlled for the use of electronic medical records, owner of the practice (physician, hospital, university, or other), and number of clinicians. Effect sizes were calculated using a pooled standard deviation with the Cohen $d$ statistic. ${ }^{15}$

\section{RESULTS}

Study patients made an average of 8.1 visits (SD, 5.3) to the practice in the preceding 2 years. On average, patients were aged 59.5 years $(\mathrm{SD}, 14.5)$ and weighed $206 \mathrm{lb}$ (SD, 51.6), with $30.2 \%$ of patients noted as overweight or obese by their physician. Slightly more than one-half $(50.9 \%)$ of the patients were female.

The median number of clinicians per practice was 4 (range, 1-34). Approximately 30\% (16) of the practices had electronic medical records. Sixty-seven percent of practices were physician owned, $23 \%$ were hospital owned, $7 \%$ were university owned, and $4 \%$ had other owners.

Diabetes flow sheets were used in $23 \%$ of medical records overall. About 39\% (21) of the practices used diabetes flow sheets for at least some patients. On average diabetes flow sheets were used for $21.4 \%$ of diabetes patients in a particular practice (range 0\%-100\%). 


\begin{tabular}{|c|c|c|c|c|}
\hline $\begin{array}{l}\text { Guideline } \\
\text { Component }\end{array}$ & $\begin{array}{l}\text { Flow Sheets } \\
\text { Used } \\
(n=234)\end{array}$ & $\begin{array}{l}\text { Flow Sheets } \\
\text { Not Used } \\
(\mathrm{n}=782)\end{array}$ & $P$ Value $^{a}$ & Effect Size ${ }^{b}$ \\
\hline Assessment & $55.38(24.64)$ & $50.13(24.99)$ & .02 & 0.212 \\
\hline Treatment & $79.59(24.35)$ & $74.71(26.16)$ & .004 & 0.042 \\
\hline Target attainment & $43.15(29.31)$ & $40.76(29.61)$ & .32 & 0.081 \\
\hline \multicolumn{5}{|c|}{$\begin{array}{l}\text { Note: Values are expressed as mean (SD) scores on scales from } 0 \text { to } 100 \text {, where higher scores indicate better } \\
\text { adherence, and are adjusted for use of electronic medical records, practice owner, and number of clinicians in } \\
\text { the practice. }\end{array}$} \\
\hline \multicolumn{5}{|c|}{ a $P$ value for generalized linear model parameter estimate. } \\
\hline \multicolumn{5}{|c|}{ b Calculated using the Cohen $d$ statistic with a pooled standard deviation. } \\
\hline
\end{tabular}

Use of a diabetes flow sheet was associated with better scores for guideline adherence in terms of diabetes assessment $(P=.02)$ and diabetes treatment $(P=.004)$, but not in terms of target attainment (Table 1). Although the associations between flow sheet use and assessment and treatment were significant, differences between the flow sheet and no-flow sheet groups were small.

\section{DISCUSSION}

This is the first study to assess the association between the use of disease-specific flow sheets and adherence to care guidelines for diabetes in the everyday practice of primary care.

Our study demonstrates that use of diabetes flow sheets may improve adherence to guidelines when it comes to assessing and treating diabetes, but not when it comes to attaining targets. Because flow sheets are tools for managing and measuring processes of care, using them increases the chance of adhering to assessment guidelines. Target scores, however, while dependent on processes of care, are influenced by other factors such as disease severity, length of time on treatment, type of treatment, ability of physicians to identify and target patients not meeting outcome targets, physician-patient relationship, frequency of visits for diabetes, patients' prescription plans, and patients' compliance. Other studies have noted that because of these patient and physician variables, improving processes of diabetes care does not necessarily translate to improved patient outcomes. ${ }^{16,17}$ Our method of creating guideline adherence scores is an innovative way of generating scores that reflect processes of care as well as clinical outcomes. Researchers who use only target outcome measures would find no detectable difference with the use of flow sheets, thus concluding they were not useful.

There are several limitations to this study. Because this is a cross-sectional study, we are unable to assess causality. It is also possible that there are additional confounders we have not controlled for. We did not collect data on specific flow sheet entries; therefore, we can only determine whether at least 1 piece of information was present on the flow sheet, but not how often they were used or when they were last used. Additionally, we do not know which practice members, if any, were trained to use flow sheets. Despite these limitations, this study is unique in examining diabetes flow sheet use in community practices.

In conclusion, our study shows that use of diabetes flow sheets is associated with increased adherence to guidelines for diabetes care and may be a valuable tool in improving patient care.

To read or post commentaries in response to this article, see it online at http://www.annfammed.org/cgi/content/full/6/3/235.

Key words: Flow sheets; diabetes mellitus; family practice; guidelines; assessment; treatment; outcomes; primary care; quality of health care; process assessment (health care); medical record review

Submitted June 5, 2007; submitted, revised, September 18, 2007; accepted September 28, 2007.

Funding support: Funding support for this work was provided by the National Heart, Lung, and Blood Institute (R01HL70800), an American Academy of Family Physicians Center Grant, the Primary Care Developing Shared Resource of the Cancer Institute of New Jersey, and the Lehigh Valley Hospital and Health Network.

Acknowledgments: This study was conducted within the New Jersey Family Medicine Research Network (NJFMRN) and the Eastern Pennsylvania Inquiry Collaborative Network (EPICnet). The authors wish to acknowledge Pamela Ohman Strickland, PhD, for statistical guidance.

\section{References}

1. Nowalk MP, Zimmerman RK, Feghali J. Missed opportunities for adult immunization in diverse primary care office settings. Vaccine. 2004;22(25-26):3457-3463.

2. Baskerville NB, Hogg W, Lemelin J. Process evaluation of a tailored multifaceted approach to changing family physician practice patterns improving preventive care. J Fam Pract. 2001;50(3):W242-W249.

3. Nasmith L, Cote B, Cox J, et al. The challenge of promoting integration: conceptualization, implementation, and assessment of a pilot care delivery model for patients with type 2 diabetes. Fam Med. 2004;36(1):40-45.

4. Ruoff G. The management of non-insulin-dependent diabetes mellitus in the elderly. J Fam Pract. 1993;36(3):329-335.

5. Ruoff G. A method that dramatically improves patient adherence to depression treatment. J Fam Pract. 2005;54(10):846-852.

6. Weyer SM, Konrad N, Esola D, Goodwin MA, Stange KC, Flocke SA. Features of medical records in community practices and their association with preventive service delivery. Med Care. 2005;43(1):28-33. 
7. Ruoff G, Gray LS. Using a flow sheet to improve performance in treatment of elderly patients with type 2 diabetes. Fam Med. 1999;31(5):331-336.

8. Stroebel CK, McDaniel RR Jr, Crabtree BF, Miller WL, Nutting PA, Stange KC. How complexity science can inform a reflective process for improvement in primary care practices. Jt Comm J Qual Patient Saf. 2005;31(8):438-446.

9. National Diabetes Education Program. Guiding Principles for Diabetes Care: For Health Care Providers. Bethesda, MD: National Diabetes Education Program; 2004. NIH publication 99-4343.

10. Ohman-Strickland PA, Hudson SV, Solberg LI, et al. Association of diabetes care with presence of nurse practitioners and physician assistants in family medicine practices. Ann Fam Med. 2008;6(1):14-22.

11. Hahn KA, Ohman-Strickland PA, Hamilton JL, Scott JG, Nazareth TA, Crabtree BF. Hyperlipidemia guideline adherence and association with patient gender. J Womens Health (Larchmt). 2006;15(9):1009-1013.

12. Crosson JC, Ohman-Strickland PA, Hahn KA, et al. Electronic medical records and diabetes quality of care: results from a sample of family medicine practices. Ann Fam Med. 2007;5(3):209-215.
13. Orzano AJ, Strickland PO, Tallia AF, et al. Improving outcomes for high-risk diabetics using information systems. J Am Board Fam Med. 2007;20(3):245-251.

14. SAS for Windows [computer program]. Version 9.1. Cary, NC: SAS Institute, Inc; 2002-2003.

15. Rosnow RL. Effect sizes for experimenting psychologists. Can J Exp Psychol. 2003;57(3):221-237.

16. Ackermann RT, Thompson TJ, Selby JV, et al. Is the number of documented diabetes process-of-care indicators associated with cardiometabolic risk factor levels, patient satisfaction, or self-rated quality of diabetes care? The Translating Research into Action for Diabetes (TRIAD) study. Diabetes Care. 2006;29(9):2108-2113.

17. Mangione CM, Gerzoff RB, Williamson DF, et al. The association between quality of care and the intensity of diabetes disease management programs. Ann Intern Med. 2006;145(2):107-116. 